\begin{tabular}{|c|c|c|}
\hline $\begin{array}{l}\text { PUCRS } \\
\text { PUC. }\end{array}$ & $\begin{array}{l}\text { ESCOLA DE } \\
\text { HUMANIDADES }\end{array}$ & $\begin{array}{l}\text { Revista Digital do Programa de Pós-Graduação em Letras da PUCRS } \\
\text { Letrônica, Porto Alegre, v. 14, n. 2, p. 1-10, abr.-jun. } 2021 \\
\text { e-ISSN: 1984-4301 }\end{array}$ \\
\hline http://dx & org/10.15448/1984-4301.2021.2.38744 & \\
\hline
\end{tabular}

SEÇÃO: ARTIGOS

\title{
O guessing game e o texto literário
}

The guessing game and the literary text

\section{Brendom da Cunha Lussani ${ }^{1}$ \\ orcid.org/0000-0003-0154-8580 \\ bclussani@gmail.com}

\section{Roberta Silveira \\ Carvalho ${ }^{2}$}

orcid.org/0000-0001-9228-057X robertasilveiracarvalho@gmail.com

Recebido em: 30 jul. 2020. Aprovado em: 7 jan. 2021. Publicado em: 10 agos. 2021.
Resumo: O presente artigo tem como objetivo, através da leitura e análise de um participante, exemplificar como o jogo cognitivo de adivinhação, originalmente guessing game, de Goodman (1976), pode ser apresentado de forma concreta. Para este artigo, utilizou-se o conto "O Homem da Favela", de Manuel Lobato, que apresenta uma narrativa que exige do leitor compreensão e atenção aos fatos narrados. O artigo está organizado de forma a apresentar a fundamentação teórica relacionado à leitura e à compreensão. Na sequência, é demonstrado por meio da leitura de um leitor, um caminho possivel para o percurso de compreensão, estabelecendo conexões entre os traços linguisticos do texto e seus conhecimentos prévios. Por último, apresentam-se as considerações finais sobre a procedimento da leitura à luz da teoria utilizada.

Palavras-chave: Leitura. Processamento. Cognição. Guessing game. Adivinhação.

Abstract: This article aims, through the reading and analysis of a participant, to exemplify how the cognitive game of divination, originally guessing game, by Goodman (1976), can be presented in a concrete way. For this article, the short story "O Homem da Favela", by Manuel Lobato, was used, which presents a narrative that requires the reader to understand and pay attention to the facts narrated. The article is organized in order to present the theoretical foundation related to reading and comprehension. Next, it is demonstrated through the reading of a reader, a possible way to the path of understanding, establishing connections between the linguistic traits of the text and its previous knowledge. Finally, the final considerations about the reading procedure in the light of the theory used are presented.

Keywords: Reading. Processing. Cognition. Guessing game. Divination.

\section{Introdução}

A leitura não pode ser reduzida apenas ao ato de decodificar sinais gráficos. Decodificar é o primeiro processo da leitura. Decodifica-se para ler. Assim, "ler é interagir, é construir significado para o texto" (DELL'ISOLA, 2001, p. 37). Ler está muito além da simples decodificação. A leitura exige do leitor conhecimento linguístico, semântico, pragmático, além de outros saberes que perpassam o saber linguistico, como o conhecimento de mundo.

Ler é, assim, uma atividade ativa e visa à compreensão do lido. Por compreensão leitora, adotamos a perspectiva de Pereira (2012) que assevera que a leitura é um processo cognitivo do qual o leitor passa a compreender o que foi decodificado, atravessando assim os limites da 
decodificação - bem como da superestrutura ${ }^{3}$, aspectos linguísticos e estilísticos do texto -, chegando às vivências do leitor e da sua intenção com o texto. Logo, leitura é uma atividade de cunho cognitivo que tem como ponto de chegada a compreensão.

Giasson (2000) aponta dois aspectos principais que distinguem os modelos tradicionais de compreensão dos modelos mais recentes. O primeiro aspecto refere-se à mudança de um modelo centrado em listas sequenciais de habilidades para um modelo mais global orientado para a integração das habilidades. O segundo aspecto diz respeito à participação do leitor na compreensão, ou seja, a interação leitor/texto.

Tradicionalmente os professores e pesquisadores adotavam como domínio da leitura o ensino das sub-habilidades de forma hierarquizada (decodificar, encontrar uma informação, destacar a ideia principal do texto etc.), para eles, dominar essas habilidades era suficiente para compreender o texto. Contudo, uma habilidade aprendida e aplicada isoladamente perde sua significação, ou seja, para formar uma imagem completa num jogo de quebra-cabeça, por exemplo, é preciso de todas as peças, uma peça isolada não consegue representar a imagem toda. Assim como as habilidades para a leitura: é preciso que o leitor use todas as habilidades de forma sincrônica, para que juntas construam a compreensão do texto.

Durante a leitura, o leitor ativa as estruturas cognitivas e afetivas que lhe são próprias e recorre a diferentes processos para compreender um texto. Entre as estruturas estão as de origem cognitiva e as afetivas. Na estrutura cognitiva o leitor guarda o seu conhecimento acerca da própria língua e do mundo que o cerca. Os conhecimentos da língua permitem que o leitor decodifique e estabeleça relações entre os enunciados e, assim, requerem domínio nos aspectos fonológico, sintático, semântico e pragmático. 0 domínio desse conjunto de habilidades linguisticas dará suporte para que o leitor decodifique o texto e estabeleça as relações necessárias com os conhecimentos do texto e os seus esquemas mentais. Já na estrutura afetiva encontramos as intenções do leitor para com o texto, ou seja, o que ele quer fazer. Uma vez que diante do texto, o leitor é livre, podendo negar ou ler o texto, tudo atrelado ao seu progresso de compreensão ao ler.

Além das estruturas supracitadas, há os processos que são utilizados de forma simultânea na leitura, que se dividem em macroprocessos (reconhecimento das palavras, leitura de grupos de palavras, micros-seleção), processos de elaboração (previsões, imagens mentais, resposta afetiva, ligação com os conhecimentos, raciocínio), processos de integração (utilização de referentes, utilização dos conectivos, inferências baseadas em esquemas), processos metacognitivos (identificação da perda de compreensão, reparação da perda de compreensão) e macroprocessos (identificação das ideias principais, resumo, utilização da estrutura do texto). Eéa partir desse conjunto de conhecimentos e ações que o leitor levanta hipóteses sobre o texto e é capaz de (re)construir o sentido.

Assumimos como atividade cognitiva a interação entre as informações e aspectos visuais e não-visuais, bem como as relações estabelecidas entre o texto e os conhecimentos prévios (ou de mundo) do leitor. Esses fatos assumem a responsabilidade de criar as inferências necessárias para que a compreensão seja alcançada. Portanto, compreender resulta "não só como a apropriação do conteúdo lido, mas como o processamento realizado pelo leitor para realizar essa apropriação" (PEREIRA, 2012, p. 82).

Neste artigo a concepção de leitura adotada tem apoio nos estudos da psicolinguística (GOODMAN, 1976; SMITH, 2003; PEREIRA, 2012). Para a literatura especializada, a leitura é um processo complexo, que envolve e engloba a compreensão pela estratégia de predição que consiste em uma racionalização metalinguística sobre a textualidade e sua construção composicional sobre os elementos fônicos, morfossintáticos,

\footnotetext{
3 Segundo Van Dijk (1978, p. 143) a superestrutura é "uma espécie de esquema ao qual o texto se adapta. Como esquema de produção isto significa que o falante sabe: 'agora contarei um conto', enquanto que, como esquema de interpretação, isto significa que o leitor não só sabe do que trata o texto, mas sobretudo, que o texto é uma narração".
} 
semânticos, pragmáticos, textuais.

Goodman (1976) enfatiza que a compreensão de um texto envolve o uso parcial de pistas mínimas disponiveis, deixadas pelo autor no texto. À medida que essas informações parciais são processadas, o leitor toma decisões provisórias para serem confirmadas, rejeitadas ou refinadas conforme a leitura avança. Em outros termos, a leitura "é um jogo de adivinhação psicolinguistica" (GOODMAN, 1976) que envolve uma interação entre pensamento e linguagem.

Para tanto, o presente artigo tem o objetivo de exemplificar a leitura do ponto de vista do processamento cognitivo do leitor diante dos traços linguísticos do material escrito, no que se refere às especificidades do gênero textual conto. Ao longo deste artigo, notamos que o leitor corrobora com a literatura, realizando a estratégia de adivinhação.

\section{A leitura e o guessing game: fundamentos teóricos}

Vincular a adivinhação à leitura pode causar surpresa, devido ao fato que o senso comum atribui à adivinhação o sentido de algo que não é confiável. Fazer adivinhações durante a leitura pode parecer, num primeiro momento, falta de seriedade e comprometimento com o texto, mas, pelo contrário, é uma estratégia de leitura que leva o leitor a antecipar ou predizer algo sobre o conteúdo.

Para Pereira (2002, p. 51),

a preditibilidade pode ser caracterizada como um jogo linguístico que ocorre durante o processo de leitura. Esse jogo situa-se no âmbito da interação do leitor com o texto, realizando-se através de jogadas que implicam apostas com diferentes graus de risco. O jogo assim estabelecido é um instrumento que o leitor utiliza para antecipação do conteúdo do texto. Faz o seu lance, isto é, prediz o que seus olhos ainda não leram, tentando adivinhar o jogo do próprio texto. Nesse momento, corre riscos cuja intensidade está associada à possibilidade de confirmação da predição realizada. Por sua vez, a dimensão da possibilidade de êxito depende de uma correlação entre as condições do leitor (universo de conhecimentos e crenças) e as pistas oferecidas pelo texto.

Ainda segundo Pereira e Santos (2017), a escolha dos sinais está apoiada no objetivo do leitor (do que ele deseja antecipar), nas características do texto (a natureza dos elementos linguísticos que o autor disponibiliza) e nos conhecimentos prévios de que o leitor dispõe para sua busca.

Goodman (1976) cunhou o termo guessing game para esse elencasse de fatores que fazem a leitura ser um jogo de adivinhação. Isso porque essa estratégia consiste numa antecipação do texto, ou seja, o leitor, com base nos conhecimentos prévios e pistas linguísticas (vocábulos, traços fônicos, estruturas morfossintáticas, sinalizações gráficas, fatores semântico-pragmáticos) deixadas pelo autor no texto, faz adivinhações sobre conteúdo do texto que ainda não foi lido. Para o autor, o processo receptivo das línguas naturais consiste em métodos alternados de estratégias de colheita de amostragem, predição, testagem e confirmação. Essas estratégias fornecem, através do uso de um número mínimo de elementos disponiveis, as predições mais confiáveis. O autor afirma que a leitura é um processo preciso, envolvendo percepção exata, detalhada e sequencial de letras, palavras e unidades linguísticas. Para isso, Goodman propôs o modelo guessing game a fim de sinalizar que a leitura eficiente não resulta da percepção e identificação precisa de todos os elementos, mas da habilidade em selecionar o menor número de pistas mais produtivas, necessárias para produzir suposições certas desde a primeira tentativa de adivinhação.

As estratégias de leitura associadas ao processamento cognitivo consistem em caminhos cognitivos e metacognitivos realizados pelo leitor em busca de compreensão. Uma revisão da literatura aponta diferentes categorizações, como ativação dos conhecimentos prévios (buscas na memória), seleção (escolha de focos no texto e de procedimentos leitores), identificações dos padrões organizacionais do texto (temas, subtemas, diagramação, distribuição do texto), predição (antecipação dos conteúdos, formulação e testagem de hipóteses), leitura detalhada (direcionamento de atenção, tempo de leitura), automonitoramento (controle da compreensão e dos procedimentos de leitura), skimming (leitura rápida, buscando conhecimento geral das 
possibilidades do texto), scanning (leitura geral do texto mas com objetivo de busca especifica), autoavaliação (julgamento da compreensão e dos procedimentos de leitura utilizados) e autocorreção (alteração dos procedimentos de leitura, considerando a compreensão obtida).

Para Pereira (2002, p. 47),

a concepção de leitura que põe a linearidade como condição de qualidade de compreensão vem sendo revista pelos estudos psicolinguisticos, no que se refere especialmente ao processamento da leitura. Tais estudos vem trazendo para a discussão um novo conceito - o de preditibilidade, que estimula a associação da leitura a um jogo de risco automonitorado em que o leitor faz suas apostas, controla-as e assim chega ao êxito.

Dessa forma, ler na perspectiva da predição é antecipar o conteúdo do texto, utilizando-se das pistas linguísticas grafofônicas, sintáticas e semânticas. O primeiro conhecimento relaciona-se aos saberes da língua verbal escrita e a capacidade de tornar os sinais gráficos em "sons mentais", atribuindo assim um valor significativo ao que está "desenhado". O segundo, conhecimento sintático, dá-se tanto pela distribuição das palavras nas sentenças e aos sinais de pontuação que ajudam o leitor a predizer. O último conhecimento está relacionado a estabelecer relações entre os termos (sentido) e a experiência do próprio leitor com o seu mundo.

Goodman (1991, p. 4), assegura que a compreensão é compartilhada:

O significado não é uma característica dos textos. Em vez disso, os textos são construidos pelos autores para serem compreendidos pelos leitores. O significado está no autor e no leitor. O texto tem um potencial de evocar significado, mas não tem significado em si mesmo. A compreensão depende de quão bem o autor constrói o texto e de quão bem o leitor o reconstrói o significado. Mas o significado não passa entre o autor e o leitor. Ele é representado por um autor em um texto e construido a partir de um texto pelo leitor. Características do autor, do texto e do leitor, todas influenciarão o significado resultante.

A compreensão é também uma questão de selecionar as estratégias de leitura que melhor auxiliam nesse processo de desvendar o texto. Nesse sentido, a predição é considerada de gran- de amplitude, na medida em que abrange outras estratégias mais especificas (PEREIRA; AMODEO, 2014). Em estudo realizado por Piccini e Pereira (2006), ao testarem a estratégia de predição, definiram-na como constituída do automonitoramento, da autoavaliação e da autocorreção. Logo o percurso cognitivo da predição exige do leitor um processo de consciência, que supõe período continuado de atenção (DEHAENE, 2012). Nesse sentido é preciso que o leitor, para estar em condição de atenção: a) esteja atento não só às pistas linguísticas do texto e aos seus próprios conhecimentos prévios, mas às antecipações que realiza da leitura, b) que mantenha sua atenção nessas antecipações, avaliando-as, do ponto de vista de sua conexão, às pistas e aos elementos prévios; e c) que modifique suas antecipações, caso julgá-las impróprias ao texto que lê. Ao realizar esses procedimentos, o leitor está imerso a um processo de intenso esforço cognitivo inferencial sobre o texto em leitura (PEREIRA; AMODEO, 2014).

A respeito disso, Goodman (1991) sinaliza que as predições são embasadas tanto em informações explícitas como inferidas, usadas de tal forma que é improvável que o leitor perceba conscientemente as informações que foram inferidas ou as que estavam explícitas. Essa estratégia de predição faz com que o processo de leitura flua suavemente à medida que o leitor constrói e reconstrói o texto e o sentido.

A proposta de leitura apresentada pelo autor se revela numa leitura não linear, visto que o leitor tem autonomia na sua leitura. Pode-se dizer que a proposta de leitura prevista pelo autor é uma estratégia cognitiva, já que presume uma adivinhação por parte do leitor que irá confirmar ou refutar a ideia pretendida pelo autor. Portanto, considera-se um leitor proficiente aquele faz mais adivinhações acertadas, já o leitor imaturo é aquele que faz uma leitura linear com pouca predição.

Reitera-se que a predição é uma condição natural do ser humano. Usamos essa estratégia no nosso dia a dia, fazendo planejamento, projetos, construindo hipóteses. Trabalhamos as adivinhações nas novelas a que assistimos, quando imaginamos o desfecho delas, por exemplo. 


\section{0 leitor e o guessing game}

Nesta seção apresenta-se o participante que realizou a leitura monitorada de um conto. Posteriormente apresenta-se o texto selecionado pelos autores do artigo e a análise do caminho da leitura realizada pelo participante.

\subsection{Participante}

Para este estudo, convidou-se um leitor proficiente da lingua materna. O participante caracteriza-se por um sujeito brasileiro, nível superior completo e filho de pais que possuem o português brasileiro como a língua materna.

\subsection{Método de análise}

Para este estudo, usou-se um texto impresso e fixado sobre uma mesa, solicitando ao leitor que realizasse a leitura e, com o auxilio de uma caneta, sublinhasse o texto à medida que a leitura progredia e seus olhos moviam-se. Durante esse processo, adotou-se a leitura silenciosa, pois foi solicitado ao participante que pronunciasse apenas o que ele estava pensando sobre o texto no momento da leitura, bem como as perguntas e considerações que surgiam ao longo da leitura. Para tanto, não anunciamos a ele a finalidade da análise da leitura, apenas explicamos como essa deveria ser feita.

Além de pronunciar o que estava pensando e questionando-se sobre o texto, o leitor deveria sinalizar com a caneta a posição em que seus olhos se fixavam para buscar respostas no texto, sendo elas antes ou após o ponto de leitura em que ele estava ao questionar ou afirmar algo.
A leitura foi realizada na presença de um dos autores deste artigo que orientou e fez observações relevantes sobre o comportamento do participante.

\subsection{Texto}

Para este estudo, utilizou-se o texto "O homem da favela" de autoria de Manuel Lobato (1989), cujo gênero é o conto. $O$ texto narra o percurso de um médico do hospital até a sua casa, após um dia de plantão. Com histórico de nove assaltos, o médico fica assustado quando vê um vulto na estrada. A partir desse momento é que a história se desenvolve.

\subsection{Caminho da leitura}

Abaixo, apresentamos a análise a partir da leitura do conto "O Homem da Favela" realizada pelo participante. Sinalizamos que a leitura aqui apresentada é a leitura individual de um participante, podendo refletir ou não a leitura de um grupo.

Para que a exposição dos recursos de leitura utilizados pelo participante se desse de forma clara, segmentamos o texto nos parágrafos que o constitui e apresentamos, na sequência, como se deu a leitura. Reiteramos que a segmentação do texto se dá somente para fins de análise e exposição da estratégia de leitura do participante. Durante a leitura, o texto foi ofertado na integra.

Ao iniciar a leitura, o participante muniu-se com a caneta ofertada e analisou o texto como um todo, fazendo um scanning, buscando compreender o texto no que tange a sua extensão, tamanho da letra e informações que pudessem lhe chamar atenção. Após ler o título, deu início à leitura do conto (ver Figura 1).

Figura 1 - Primeiro parágrafo do conto

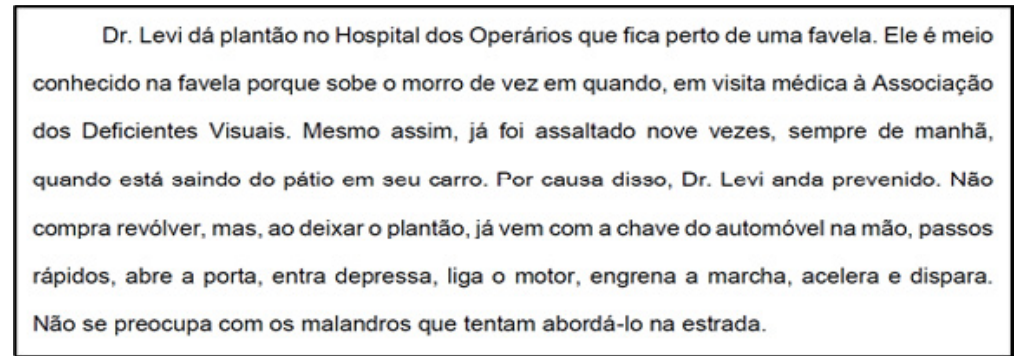

Fonte: Lobato (1989).

O início da leitura é marcado pela indagação do leitor sobre o plantão e satisfeito logo em seguida. Pronuncia o termo "operários", como se precisasse reafirmar de onde é o hospital (leitura detalhada). O leitor, aqui, mostra-se determinado a colher todas as pistas que o texto traz, dá-se conta que 
algo pode surpreendê-lo e exigir que monte um "quebra-cabeça" ainda desconhecido para ele.

Ao informar-se que o médico é conhecido, interroga-se "conhecido de quem?" em confronto da informação de já ter sido assaltado nove vezes, como apresentado no texto (estratégia de skim- ming, em que o leitor passa os olhos pelo texto, buscando identificar sua ideia geral; inferência). Quando descobre que Dr. Levi anda prevenido, acelera-se para encontrar de que forma ele está se protegendo dos assaltos, já que a opção porte de arma é descartada pela personagem.

Figura 2 - Segundo parágrafo do conto

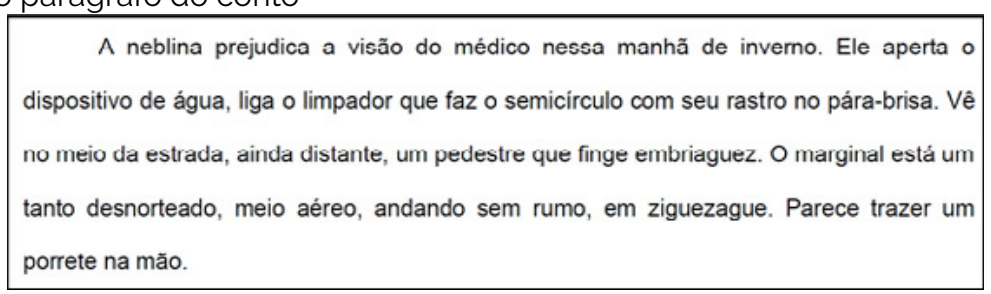

Fonte: Lobato (1989).

O leitor surpreende-se com a informação sobre o periodo do dia (manhã) (ver Figura 2) recorre ao texto já lido (scanning, skimming) e não encontra nenhuma informação anterior que já acusasse o periodo do dia. Segue sua leitura atenta. Dado que a narrativa introduz uma nova personagem, classificada como marginal, questiona a posição do médico sobre a previsão da embriaguez da personagem (o marginal).

O termo ziguezague reafirma ao leitor a ideia de julgamento antecipado do médico (leitura detalhada) sobre o vulto que vê na estrada. 0 leitor toma como justificativa a passagem que abre o parágrafo (A neblina prejudica a visão do médico) e infere que o médico está baseando-se apenas nas suas crenças sobre as pessoas, em especial as que moram na favela.

A presença de um porrete, informado em uma única sentença, também contribui para destacar o possivel preconceito do médico em relação ao vulto. O leitor recorre ao título do texto (skimming) para confirmar sua teoria de pré-julgamento do médico e confirmar a sua teoria de que o vulto não se trata de um bêbado (inferência).

Figura 3 - Terceiro parágrafo do conto

Dr. Levi será obrigado a diminuir a aceleração e a reduzir a marcha. Se o mau elemento continuar na pista, terá de frear. Se parar, poderá ser assaltado pela décima vez. O carro se aproxima do malandro. Ele usa boné com o bico puxado para frente, cobrindo-lhe a testa. Óculos escuros para disfarce, ensaia os cambaleios, tomba um pouco a cabeça, olha para cima, procura o sol que está aparecendo, sem pressa, com má vontade.

Fonte: Lobato (1989).

O leitor dá sequência a sua leitura (ver Figura 3), reforça a ideia de ser assaltado pela décima vez. Nesse momento percorre o texto (skimming) para confirmar se o médico já havia anunciado nove assaltos e satisfaz-se ao encontrar a informação que procura. Dá ênfase à vestimenta do homem que anda pela rua (leitura detalhada, automonitoramento), como se buscasse associar as vestimentas a algum elemento anterior do texto. Propõe uma inferência com o vestuário anunciado, mas sem sucesso dá sequência à leitura.

Baseando-se no que lê, reformula a hipótese (automonitoramento, autoavaliação) e agora passa a dividir o mesmo pensamento que o médico: o vulto está fazendo-se de bêbado e irá assaltar o médico. Tal mudança de percepção é motivada, em especial, pela descrição de "má vontade" da pessoa em sair da pista de rolamento.

A leitura segue para o seu clímax (ver Figura 4). 
Figura 4 - Quarto e quinto parágrafo do conto

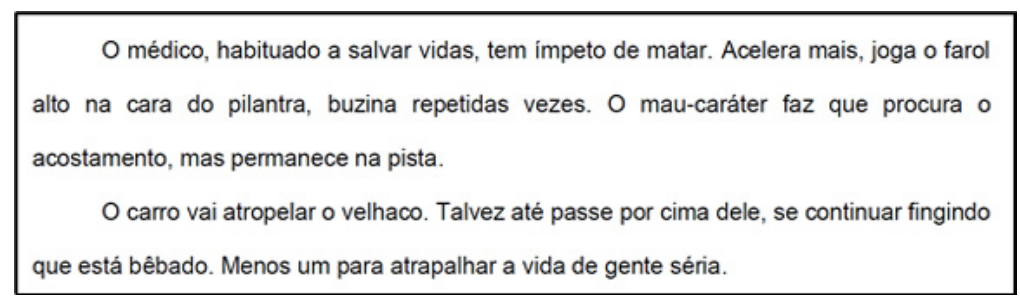

Fonte: Lobato (1989).

Já com a mesma percepção do médico, o leitor acredita veemente que o "pilantra" será atropelado, pois o médico sentiu-se ameaçado pelo vulto. O leitor retoma a expressão "porrete na mão" e infere que, assim como o médico, há sinal de perigo. Reforçando assim que não se trata de um bêbado, mas um futuro assalto.

Nesse momento, o leitor retoma a passagem da primeira linha sobre o médico ser conhecido (skimming, automonitoramento), acessa seus conhecimentos já adquiridos ao longo da leitura e infere que, se o médico é conhecido, logo todos sabem que ele já fora assaltado nove vezes, configurando-se assim, uma vítima "fácil", uma vez que escolheu não se armar.

Segue a leitura confiante nas suas conclusões até o momento (ver Figura 5).

Figura 5 - Sexto e sétimo parágrafo do conto

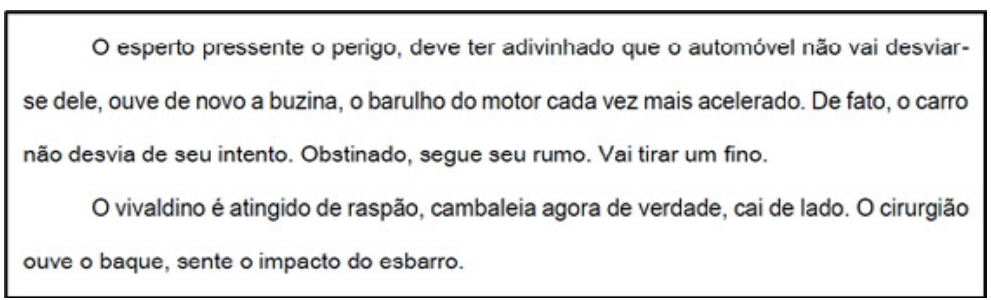

Fonte: Lobato (1989).

Ao deparar-se com os parágrafos acima, o leitor sinaliza apreensão quanto ao desenrolar do conto, pois nota que o conto já está na sua metade (scanning).

Ao passo que a leitura progride, mantém a ideia de um possivel atropelamento (predição), porém descarta a ideia de que o médico matará a personagem que está na rua com a afirmação "vai tirar um fino" (inferência). Ao descartar a morte de uma das personagens, o leitor acessa informações pessoais sobre "tirar um fino" ser aproximar-se muito perto de algo, não necessariamente atingir.
O leitor segue a leitura com algumas certezas: a) o médico corre perigo de ser assaltado pela personagem que está na rua; b) a personagem da rua está se fingindo de bêbada para assaltar o médico; c) o médico está se sentindo ameaçado e com medo - visto que a personagem da rua está munida de um porrete e pode usá-lo para assaltá-lo; e d) o médico irá passar com o carro muito próximo da pessoa que está fingindo-se de bêbada na rua. Todas as certezas baseiam-se na leitura detalhada e no automonitoramento feito pelo leitor (ver Figura 5).

Figura 6 - Oitavo parágrafo do conto

Vê pelo retrovisor interno a vítima caída à beira da estrada $O$ vidro de trás está embaçado, mas permite distinguir o vulto, imagem refratada. Gotas de água escorrem pelo vidro não como lágrimas, e, sim, como bagas de suor pelo esforço da corrida. Não há piedade, há cansaço.

Fonte: Lobato (1989). 
O leitor, munido de suas verdades baseados no texto, surpreende-se com o termo "lágrima" e atrapalha-se na compreensão (ver Figura 6), pois nota-se que ele associou a palavra "lágrimas" com tristeza, sentimento que o médico poderia ter tido ao ver que atropelara a pessoa que o ameaçava. Porém, logo corrige (automonitoramento, autocorreção) a sua compreensão com a leitura do termo "suor" e ressignifica sua hipótese inicial de sentimentalismo do médico.
Demora-se no termo "cansaço" e percorre o texto para buscar uma explicação do porquê o médico estar cansado (scanning, skimming). Descarta a ideia do plantão que é apresentada no início do texto e relaciona o cansaço com as decisões que o médico teve que tomar nos últimos instantes: a) atropelar o "velhaco" que agia de má vontade e livrar-se do possivel décimo assalto ou b) manter-se indiferente com a situação e ser possivelmente assaltado pela décima vez. O leitor retoma o texto, fazendo tais indagações e conclui que essas opções levaram o médico ao cansaço.

Figura 7 - Nono parágrafo do conto

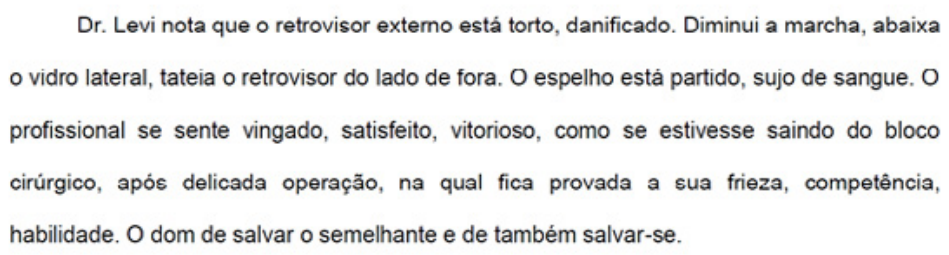

Fonte: Lobato (1989)

Ao notar que existe sangue no retrovisor (ver Figura 7), reformula sua hipótese de que o médico iria apenas "tirar um fino" (leitura detalhada, automonitoramento, autoavaliação) e agora acredita no atropelamento. Reforça a nova possibilidade, retornando ao parágrafo anterior e relê "vítima caida à beira da estrada". Agora, corrige novamente a sua hipótese: o médico não somente atropelara o possivel assaltante, mas também o matara. Confirma sua hipótese com o termo "vingado", inferindo, assim, que o médico se sentiria vingado daquele que é possivel ver pelo retrovisor e de todas as outras nove vezes que fora assaltado.

Com a certeza do atropelamento, corrige a sua percepção sobre o médico que anteriormente afirmara ser sério (autoavaliação). O leitor passa a não mais creditar o adjetivo "sério" ao médico por ele ter atropelado alguém. Nota-se aqui um julgamento de valor pessoal do leitor sobre o que é ser médico e o comportamento que este deve assumir.

Figura 8 - Décimo parágrafo do conto

No dia seguinte, ao cair da tarde, chega o plantonista ao Hospital dos Operários. Toma

conhecimento do acidente. O paciente - algumas fraturas, escoriações - está fora de perigo.

Deu entrada ontem de manhã, mal havia chegado o substituto do Dr. Levi.

Fonte: Lobato (1989)

O avanço temporal do conto (no dia seguinte; ver Figura 8) excita o leitor a desvendar o fim dos acontecimentos, questionando-se "o que aconteceu no dia seguinte?". Relaciona o plantonista ao médico e ao termo "manhã" lido em parágrafos anteriores. Relacionando assim que a má visão do médico pode estar associada, também, ao plantão que exerce no Hospital dos Operários.

Ao descobrir que sabem quem é o atropelado (o paciente), o leitor interroga-se em tentar saber quem é (leitura detalhada). Percorre o texto em busca de uma informação que pudera ter deixado passar despercebido, porém sem sucesso segue a leitura.

A partir deste momento o leitor começa a confir- 
mar as suas hipóteses levantadas até agora a partir das informações conhecidas do texto: a) o médico corria perigo de ser assaltado pela personagem que estava na rua; b) a personagem da rua estava se fingindo de bêbada para assaltar o médico; c) o médico estava se sentindo ameaçado e com medo - visto que a personagem da rua estava munida de um porrete; e d) o médico atropelou a personagem que estava na rua, matando-a.

A hipóteses "d" é descarta pelo leitor ao ler que o paciente está "fora de perigo", então ele retoma a sua ideia inicial de que o médico apenas tiraria um fino do possivel assaltante. Porém, ainda se questiona por que a personagem permanecera deitada na estrada se não estava morta. Aguarda a conclusão da indicação com o avanço da leitura (ver Figura 9).

Figura 9 - Décimo primeiro parágrafo do conto

$\mathrm{Na}$ ficha, anotações sobre a vítima: funcionário da Associação. Seus pertences: recibo

das mensalidades, uns trocados, óculos e bengala. Cego.

Fonte: Lobato (1989).

Ao ter acesso às informações que descrevem o atropelado, surpreende-se com a forma que fora enganado pela visão errada do médico. Quando toma conhecimento de que o atropelado é funcionário da Associação, relaciona direto à Associação de Deficientes Visuais - informação que está presente na segunda linha do conto.

Concluida a leitura dos pertences da personagem atropelada, descarta todas as hipóteses feitas ( $a, b$ e c) e retoma ao texto a fim de confirmar que o atropelado era um cego e não um assaltante.

Assim, acaba por relacionar a embriaguez à possivel preocupação do cego ao ouvir a buzina que o médico aciona, os óculos escuros por ser um acessório muito usado pelos deficientes visuais e a bengala, antes creditada como porrete, o auxilio do funcionário durante sua locomoção.

O leitor conclui a sua leitura vasculhando essas informações no texto para confirmar a descoberta da identidade do atropelado, corrigindo assim, suas hipóteses.

\subsection{Resultado e discussão}

Com base na observação do caminho percorrido pelo leitor durante a leitura, contata-se o uso simultâneo das estratégias de leitura, como skimming, automonitoramento, autoavaliação, scanning, predição e a inferência. De acordo com os teóricos da psicolinguística, para a compreensão eficiente de um texto, faz-se necessário o uso de estratégias. Essas estratégias não são hierárquicas, mas acionadas de acordo com as necessidades que o leitor tem para continuar compreendendo o texto.

Diante do percurso realizado pelo leitor, verifica-se a aplicação do guessing game diversas vezes durante a compreensão leitora. O leitor não apenas inferiu informações, como refutou diversas hipóteses e se utilizou do automonitoramento como a autocorreção. Essa aplicação mostra que as estratégias como o guessing game, utilizado várias vezes, são fundamentais para a compreensão eficiente de um texto.

\section{Considerações finais}

O objetivo do presente artigo foi apresentar a leitura com o guessing game e como ela pode contribuir para a sua compreensão. No teste de leitura aqui apresentado, nota-se que o participante ao longo da leitura criava hipóteses e, conforme o conto fornecia embasamento, confirmava ou refutava tais afirmações.

Chama-se a atenção para o fato de que na metade do conto o leitor já havia estabelecido "suas verdades" a partir dos elementos do texto, na perspectiva do médico, deixando passar informações que já poderiam ter auxiliado a compreender que o homem que estava na rua não era um perigo, caso tivesse relacionado à Associação de Deficientes Visuais logo de início. A associação cogitada por nós e que auxiliaria na leitura é a de que deficientes visuais fazem uso dos elementos que o médico destaca que o homem trazia consigo. A bengala, por exemplo, 
foi compreendida de forma errônea por parte do médico, visto que havia neblina na manhã.

Contudo, ao final deste artigo, notamos que a teoria proposta por Goodman (1976) parece até hoje necessária para a compreensão leitora. Neste estudo pudemos demonstrar que ouve um "jogo de adivinhação" por parte do participante que, diversas vezes, propôs uma hipótese e, à medida que a leitura ia avançando, confirmava ou refutava suas suposições.

\section{Referências}

DEHAENE, Stanislas. Os neurônios da leitura: como a ciência explica a nossa capacidade de ler. Porto Alegre: Penso, 2012.

DELL'ISOLA, Regina Lúcia Péret. Leitura: inferências e contexto sociocultural. Belo Horizonte: Formato Editorial, 2001

GIASSON, Jocelyne. A compreensão na leitura. 2. ed. Tradução de Maria José Frias. Porto: ASA, 2000.

GOODMAN, Kenneth S. Um jogo psicolinguístico de adivinhação. In: SINGER, Harry; RUDDELL, Robert B. (org.) Theoretical models and processes of reading. v. 2. Newark: International Reading Association, 1976. p. 259-271.

GOODMAN, Kenneth S. Unidade na leitura: um modelo psicolingüistico transacional. Letras de Hoje, Porto Alegre, v. 26, n. 4, p. 9-43, dez. 1991.

LOBATO, Manoel. O homem da favela. In: LEITE, Alcione Ribeiro (org.). O fino do conto. Belo Horizonte: RHJ, 1989.

PEREIRA, Vera Wannmacher. A predição na teia de estratégias de compreensão leitora. Confluência, Rio de Janeiro. v. 1, p. 81-91, 2012.

PEREIRA, Vera Wannmacher. Arrisque-se... Faça seu jogo. Letras de Hoje, Porto Alegre, v. 37, n. 2, p. 47-63, jun. 2002

PEREIRA, Vera Wannmacher; AMODEO, Maria Tereza. O desejável jogo cognitivo de adivinhação na leitura de A carteira, de Machado de Assis. Acta Scientiarum: Language and Culture, Maringá, v. 36, n. 4, p. 437-449, nov. 2014. https://doi.org/10.4025/actascilangcult.v36i4.22709

PEREIRA, Vera Wannmacher; SANTOS, Thais Vargas dos. Estratégia de leitura de predição na escola: uso e consciência linguistica no seu uso. Linguagem em (Dis)curso, Tubarão, v. 17, n. 3. p. 361-380, set./dez., 2017. https://doi.org/10.1590/1982-4017-170305-2117

PICCINI, Maurício da Silveira; PEREIRA, Vera Wannmacher. Preditibilidade: um estudo fundado pela Psicolingüística e pela Informática. Letras de Hoje, Porto Alegre, v. 41, n. 2, p. 305-324, 2006.

SMITH, Frank. Compreendendo a leitura: uma análise psicolinguística da leitura e do aprender a ler. 4. ed. Tradução de Daise Batista. Porto Alegre: Artmed, 2003.
VAN DIJK, Teun A. La ciencia del texto: un enfoque interdisciplinario. Barcelona: Paidós, 1978.

\section{Brendom da Cunha Lussani}

Mestre em Linguística pela Universidade Católica do Rio Grande do Sul (PUCRS), em Porto Alegre, RS, Brasil; doutorando em Letras, na Universidade de Santa Cruz do Sul (UNISC), em Santa Cruz do Sul, RS, Brasil; professor de Lingua Portuguesa da Rede Pública Estadual do Rio Grande do Sul, em Santa Clara do Sul, RS, Brasil.

\section{Roberta Silveira Carvalho}

Mestra em Linguística pela Universidade Católica do Rio Grande do Sul (PUCRS), em Porto Alegre, RS, Brasil; professora de Lingua Portuguesa da Rede Pública Estadual do Rio Grande do Sul, em Porto Alegre, RS, Brasil.

\section{Endereço para correspondência}

Brendom da Cunha Lussani

Escola Estadual de Ensino Médio Santa Clara

Rua Coronel Diel, 373

Centro, 95915-000

Santa Clara do Sul, RS, Brasil

Os textos deste artigo foram revisados pela Poá Comunicação e submetidos para validação do(s) autor(es) antes da publicação. 